\title{
ESTUDO COMPARATIVO DAS PROVAS DE SABIN-FELDMAN (SF) E IMUNOFLUORESCENCIA INDIRETA (IFI) COM A DE HEMAGLUTINAÇÃO (HA) PARA A AVALIAÇÃO DE ANTICORPOS ANTI-TOXOPLASMA EM SOROS DE CÃES
}

\author{
Masaio Mizuno ISHIZUKA * \\ Omar MIGUEL * \\ Dalton França BROGLIATO **
}

\begin{abstract}
RFMV-A/15
ISHIZUKA, M. M. et al. - Estudo comparativo das provas de Sabin-Feldman (SF) e imunofluorescência indireta (IFI) com a de hemaglutinaçāo ( $H A$ ) para a avaliação de anticorpos anti-toxoplasma em soros de cães. Rev. Fac. Med. vet. Zootec. Univ. S. Paulo, 11:133-38, 1974

Resumo: As avaliaçōes qualitativas e quantitativas da prova de $H A$ foram realizadas comparativamente às de $S F$ e IFI.

Foram examinados 80 soros de cães pelas 3 técnicas tendo sido detectados $86 \%$ de concordancia entre $\mathrm{SF}-\mathrm{HA}$ e $92 \%$ de concordancia entre IFI-HA.

Os titulos de anticorpos apresentaram resultados concordantes ou afastados no máximo a uma diluição em $94 \%$ quando relacionado $\$ F-H A$ e $97 \%$ quando da IFI-HA.

A prova de HA dada a facilidade de execução e fácil padronização do antigeno, torna-a recomendável para a rotina juntamente com a prova de IFI.
\end{abstract}

UNITEgmos: Toxoplasmose *; Sabin-Feldman (SF)*; Imunofluorescência indireta $(I F I) *$; Hemaglutinaçāo $(H A) *$.

I - I N T R O D U C A O

Os resultados encontrados $\mathrm{cm}$ trabalho anterior por ISHIZUKA, M.M. et al. 4 (1974), ao comparar as provas de Sabin-Feldman e Imonofluorescência Indircta, conduziram; a testar estas duas provas comparativamente a de Hemaglutinação.

A Hemaglutinação foi adaptada para diagnóstico da Toxoplasmose por JACOBS
\& LUNDE $^{5}$ (1957), e a facilidade de execuçāo e boa reprodubilidade justificaram o interesse de LEWIS \& KESSEL 7 (1961); CHORDI, A. et al. ${ }^{3}$ (1964); KOBAYASHI et al. ${ }^{\circ}$ (1971) de aprimorarem a Técnica no que respeita a obtençāo do antígeno. Tal foi o sucesso, que atualmente, a prova de hemaglutinação é utilizada tanto para fins diagnósticos como em estudos

- Professor Assistente Doutor.

- Técnico de Laboratório.

Departamento de Medicina Veterinária Preventiva e Saúde Animal da Faculdade de Me. dicina Veterínária e Zootecnia da USP. 
ISHIZUKA, M. M. et al. - Estudo comparativo das provas de Sabln-Feldman (SF) e Imunofluorescencla indireta (IFI) com a de hemaglutlnaçáo (IIA) para a avaliaçăo de antlcorpos anti-toxoplasma em soros de cães. Rev. Fac. Med. vet. Zootec. Univ. S. Paulo, $11: 133-38,1974$

imuno-epidemiológicos em populaçōes animais MIYAZATO, E. ${ }^{10}$ (1971) e MCILWAIN, P. et al. ${ }^{9}$ (1969).

Em 1974, CAMARGO, M.E. et al. ${ }^{2}$, introduziram modificaçōes na prova de hemaglutinação, obtendo antigenos estáveis e de fácil padronização. Consideramos oportuno o estudo da prova de hemaglutinaçāo como padronizaçāo por CAMARGO, M.E. 2 (1974) comparativamente às provas de $\mathrm{SF}$ e imunofluorescência indireta em soros de cães.

De acordo com a hipótese de nulidade não haveria relação entre os resultados de SF-HA e IFI-HA.

A nossa hipótese de trabalho admitia a existência de uma relação positiva entre os resultados de SF-HA e IFI-HA.

Fixamos em 0,05 o nivel de rejeição da hipótese de nulidade.

\section{II - MATERIAL E METODOS}

\section{III) Soros}

Foram testados pelas 3 técnicas, 80 amostras de soros de cães enviados ao Ambulatório Clinico da Faculdade de Medicina Veterinária e Zootecnia da Universidade de São Paulo, sem distinção de raça, peso e sexo.

\section{$\left.\mathrm{II}_{2}\right)$ Reação de Sabin-Feldman}

Realizada segundo Sabin \& Feldman (1948).

\section{$\left.\mathrm{II}_{3}\right)$ Reaçāo de Hemaglutinaçāo}

Realizada segundo JACOB \& LUND : modificado por CAMARGO, M.E. et al. ${ }^{2}$ (1974). A modificaçāo consistiu na formolizaçāo de hemácias sensibilizadas para permitir liofilização posterior.

\section{Reaçäo de Imunofluorescîncia Indireta}

Realizada segundo ISHIZUKA, M.M. et al. 4 (1974).

$$
\text { III - R E S U L T A D O S }
$$

Inicialmente, classificamos os soros apenas em positivos e negativos, a uma diluição de 1:16 para aquilatarmos do comportamento qualitativo dos soros diante das 3 provas. Os resultados estão expressos nas Tabelas I e II.

T A B E L A I

Soros de căes, segundo resultados das provas de SF e HA. Săo Paulo, 1974.

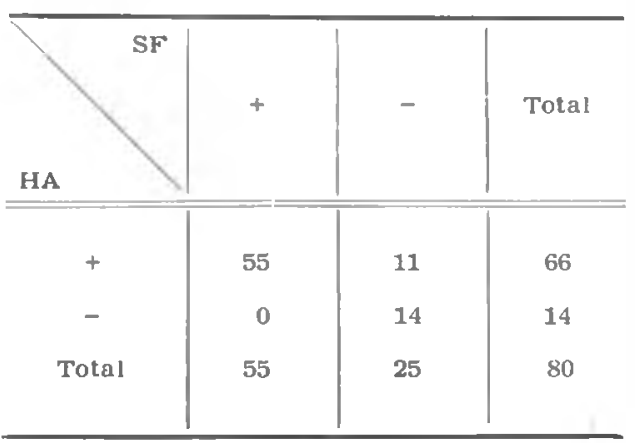

T A B E L A I I

Soros de cães, segundo resultados das provas de IFI e HA. Såo Paulo, 1974.

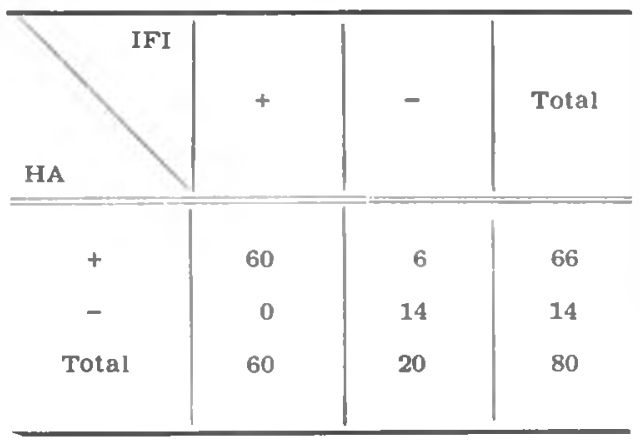


ISHIZUKA, M. M. et al. - Estudo comparativo das provas de Sabin-Feldman (SF) e imunofluorescéncia Indireta (IFI) com a de hemaglutinaçăo (HA) para a avalíação de anticorpos anti-toxoplasma em soros de cảes. Rev. Fac. Med. vet. Zootec. Univ. S. Paulo, $11: 133-38,1974$.

Os coeficientes de associação de Yule, calculado segundo MARASCUILLO ${ }^{8}$ (1971) para os dados constantes das Tabelas I e II, mostraram-se igual a 1 , sendo que as provas SF-HA apresentaram resultados concordantes em 69 soros $(86 \%)$ e os restantes 11 foram HA (+) e SF (-); as provas IFI-HA apresentaram resultados concordantes em 74 soros $(92 \%)$ e os restantes 6 foram IFI (-) e HA $(+)$.

Os valores de $\mathrm{X}^{2}$, calculados com base aos dados das Tabelas I e II, foram respectivamente iguais a 42,98 e 33,25 , que comparados ao valor crítico de $\mathrm{X}^{2}$ para 1 grau de liberdade foi significante, ultrapassando de muito o valor para o nivel de rejeição adotado.

Para uma segunda análise do problema, procuramos estudar o comportamento dos títulos de anticorpos anti-toxoplasma (recíproca da diluição) medidos pelas 3 técnicas, calculando-se para tanto a concordância dos títulos de anticorpos. Para tal estudo baseamo-nos nos dados constantes das Tabelas III e IV.

T A B E L A I I I

Títulos de anticorpos anti-toxoplasmas de soro de cães, segundo provas de SF-HA. Sảo Paulo, 1974.

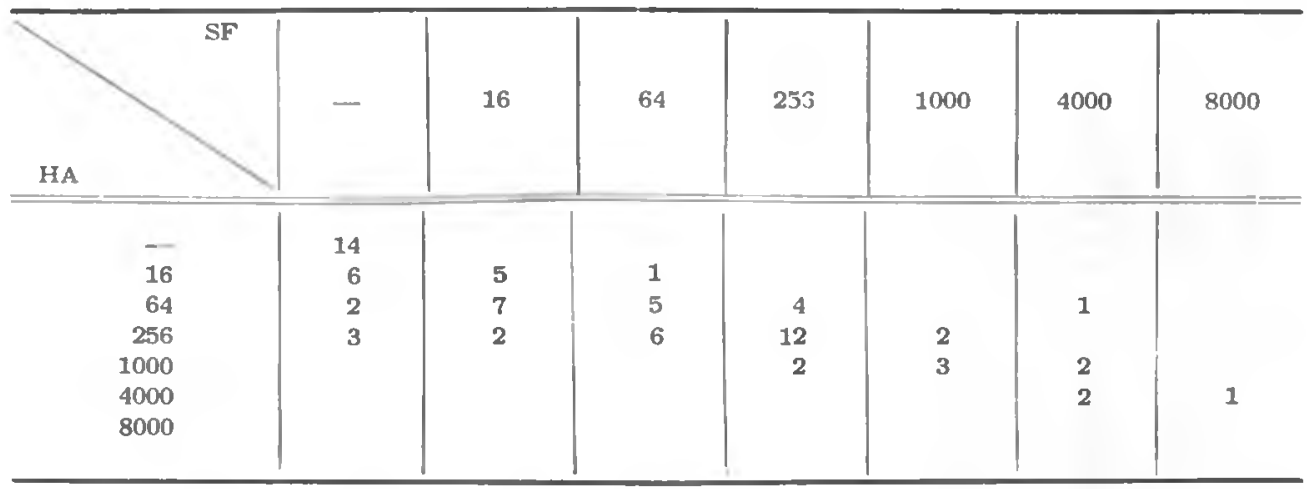

T A B E L A I V

Titulos de antlcorpos anti-toxoplasma de soros de cảes, segundo provas de IFI-HA. São Paulo, 1974.

\begin{tabular}{r|r|r|r|r|r|r|r|}
\hline & & & & & \\
\hline
\end{tabular}


ISHIZUKA, M. M. et al. - Estudo comparativo das provas de Sabin-Feldman (SF) e imunofluorescência indireta (IFI) com a de hemaglutinaçăo (HA) para a avallaçăo de anticorpos anti-toxoplasma em soros de cães. Rev. Fac. Med. vet. Zootec. Univ. S. Paulo, 11:133-38, 1974 .

Relacionando as provas SF-HA e observando a Tabela III, notou-se a existência de $49 \%$ de soros com títulos de anticorpos concordantes tendo sido $45 \%$ dos soros positivos com uma diluiçāo de discrepância e apenas $6 \%$ que se afastaram em 2 diluiçōes.

Relativamente às provas IFI-HA, com base a Tabela IV, $57 \%$ dos soros positivos apresentaram titulos de anticorpos concordantes; $4 \%$ dos soros apresentaram uma diluiçāo de discrepáncia e apenas 3\% afastaram-se em 2 diluições.

Prosseguindo na análise quantitativa dos resultados dos títulos de anticorpos antitoxoplasma calculamos a correlação existente valendo-nos para tanto do método estatístico não paramétrico pelo cálculo do coeficiente de correlação de Spearman, segundo MARASCUILLO ${ }^{8}$ (1971) com base aos dados da Tabela $\mathrm{V}$.

T A B E L A V

Titulos de antlcorpos anti-toxoplasma medidos pelas provas SF-IFI e HA. São Paulo, 1974.

\begin{tabular}{l|r|r|r|r|r|r|r|r|r}
\hline SF & IFI & HA & SF & IFI & IIA & SF & IFI & HA \\
\hline & & & & & & \\
16 & 16 & 16 & 64 & 16 & 256 & 256 & 256 & 256 \\
16 & 16 & 16 & 64 & 64 & 256 & 256 & 256 & 256 \\
16 & 16 & 16 & 64 & 16 & 64 & 256 & 1000 & 1000 \\
16 & 256 & 256 & 64 & 64 & 256 & 256 & 1000 & 1000 \\
16 & 64 & 64 & 64 & 256 & 256 & 256 & 256 & 64 \\
16 & 256 & 64 & 64 & 64 & 64 & 256 & 256 & 256 \\
16 & 64 & 16 & 64 & 16 & 16 & 256 & 256 & 256 \\
16 & 16 & 64 & 64 & 256 & 64 & 256 & 64 & 64 \\
16 & 16 & 64 & 256 & 256 & 256 & 1000 & 1000 & 1000 \\
16 & 16 & 64 & 256 & 64 & 64 & 1000 & 1000 & 1000 \\
16 & 16 & 64 & 256 & 64 & 64 & 1000 & 1000 & 1000 \\
16 & 64 & 16 & 256 & 1000 & 256 & 1000 & 1000 & 256 \\
16 & 64 & 64 & 256 & 256 & 256 & 1000 & 256 & 256 \\
16 & 64 & 256 & 256 & 1000 & 256 & 4000 & 4000 & 1000 \\
64 & 256 & 64 & 256 & 256 & 256 & 4000 & 4000 & 64 \\
64 & 16 & 64 & 256 & 256 & 256 & 4000 & 8000 & 4000 \\
64 & 64 & 256 & 256 & 64 & 256 & 4000 & 1000 & 1000 \\
64 & 64 & 256 & 256 & 256 & 256 & 4000 & 4000 & 4000 \\
& & & & & & 8000 & 8000 & 4000 \\
& & & & & & & & \\
\hline
\end{tabular}

Os coeficientes de correlaçäo de Spearman forneceram respectivamente os valores de 0,79 e 0,77 para as relações de provas SF-HA e IFI-HA. Isto indica a existência de uma correlaçāo positiva entre os métodos estudados. Estas correlações mostraram-se significantes ao nivel adotado de $5 \%$, tendo dado para a estatística " $t$ " de student, os valores 7,77 para a relação SF-HA e 9,19 para IFI-HA (o valor crítico de " $t$ " para o nivel de rejeição adotado é igual a 1,96).

$$
\text { IV - D I S C U S A O }
$$

Os resultados apresentados nas Tabelas I, II, III e IV demonstraram haver boa concordancia entre os resultados qualitativos (Tabela I e II), bem como entre os 
ISHIZUKA, M. M. et al. - Estudo comparativo das provas de Sabin-Feldman (SF) e imunofluorescéncia indireta (IFI) com a de hemaglutinação (HA) para a avaliaçăo de anticorpos antl-toxoplasma em soros de cāes. Rev. Fac. Med. vet. Zootec. Univ. S. Paulo, $11: 133-38,1974$

títulos de anticorpos (Tabela III e IV), medidos pelas 3 técnicas.

Na Tabela I, tivemos 11 casos $\mathrm{HA}+\mathrm{e}$ SF- e na Tabela II, 6 casos IFI + e SF-. Neste caso nāo se pode afastar a possibilidade de as provas de HA e IFI apresentarem maior sensibilidade que a SF, bem como uma possivel diversidade da natureza dos anticorpos envolvidos, conforme mencionado por CALERO, J.R. \& GUTIERREZ, M.J.A. ${ }^{1}$ (1966).

O estudo das correlaçōes medidas pelo coeficiente de correlação de Spearman, com os valores da Tabela $\mathrm{V}$, mostrou existir uma correlaçāo positiva significante entre os resultados obtidos pelas provas quando relacionamos SF-HA e IFI-HA. Além disso, a intensidade das correlaçōes foram elevadas.

As avaliaçōes realizadas em termos de concordáncia e correlação bem como a facilidade de execução, dispensando inclusive a utilização de equipamentos dispendiosos, permite-nos recomendar a técnica de $\mathrm{HA}$, na rotina de diagnóstico de toxoplasmose canina.

Laboratórios equipados com microscópios de fluorescência podem se valer das 2 provas com finalidade diagnóstica, pois os títulos de anticorpos medidos por ambos os métodos aproximam-se bastante.

RFMV-A/15

Ishizuka, M. M. et al. - Comparison of the Sabin-Feldman, indirect fluorescent antibody test and hemagglutination test for detection of antibodies to Toxoplasma gondii in dog serum. Rev. Fac. Med. vet. Zootec. Univ. S. Paulo, $11: 133-38,1974$

SUMMARY: The results of the $H A$ test were compared qualitativly and quantitativly with SF and IFI tests.

Eighty canine serum samples were tested by the three techniques. There was an agreement of over $86 \%$ in SF-HA and $92 \%$ in IFI-HA tests. At a difference of one dilution (four-fold) there was $94 \%$ agreement in antibody titers between the $S F-H A$ tests and $97 \%$ agreement in antibody titers between the IFI-HA tests.

UNITERMS: Toxoplasmosis*; Sabin-Feldman (SF)*; Indirect fluorescent antibody test *; Hemagglutination test (HA).

\section{REFERENCIAS BIBLIOGRAFICAS}

1. CALERO, J. R. \& GUTIERREZ, J. A. M. - Estudio de las fracciones de los anticorpos $(\gamma \mathrm{M} ; \gamma \mathrm{A} ; \gamma \mathrm{G})$ responsables de las pruebas serologicas en la toxoplasmosis; Immunofluorescencla indireta, Hemoaglutination y Dye Test. Rev. iber. Parasit., 26 (4) :391-403, 1966 .
2. CAMARgo, M. E. (1974) [no prelo].

3. CHORDI, A. et al. - Studies on the speclficity of the Indirect Hemaglutination test for toxoplasmosis. $J$. Immunol., 93:1024-33, 1964.

4. ISHIZUKA, M. M. et al. (1974) - Estudo comparativo entre as provas de 
ISHIZUKA, M. M. et al. - Estudo comparativo das provas de Sabin-Feldman (SF) e Imuno^luorescência indireta (IFI) com a de hemaglutinação (HA) para a avallaçăo de antlcorpos antl-toxoplasma em soros de căes. Rev. Fas. Med. vet. Zootec. Univ. S. Paulo, $11: 133-38,1974$.

Sabin-Feldman e Imunolluorescência Indireta para avallaçao de antlcorpos anti-toxoplasma em soros de cães. 1974. [no prelo]

5. JACOBS, L. \& LUNDE, M. M. - He. magglutination test for Toxoplasmosis. J. Parasit., 43:308-14, 1957.

6. KOBAYASHI, A. et al. - Comparison of the Dye Test and Hemagglutination tests by three different techniques in the serologic diagnosis of toxoplasmosis. Jap. J. med. Sci. Biol., 24:115-24, 1971.

7. LEWIS, W. P. et KESSEL, J. F. - Hemagglutination in the diagnosis of toxoplasmosis and ameblasis. Arch. Ophtal., 66:471-6, 1961.

8. MARASCUILLO, L. A. - Statistical methods for behavioral science re- search. New York, Mc Graw-Hill, 1971.

9. McILWAIN, P. et al. - Prevalence of antlbodies to Toxoplasma gondii in domestic animals of North Dakota. Arch. Environm. Hlth., 19:885-6, 1969.

10. MIYAZATO, E. - Immuno-epidemiological studies on Toxoplasmosis inOkinawa. Trop. Med. Nagasaki, 12: 210-20, 1971 .

11. SABIN, A. B. \& FELDMAN, H. A. Dyes as michrochemical indicators of a new immunity phenomenon affecting a protozoan parasite (Toxoplasma). Science, 108:660, 1948.

Recebldo para publlcaçăo em 28-8-74 Aprovado para publícaçüo em 29-8-74 